\title{
Dynamics and transformations of the Moroccan immigration in the world: a synthetic overview
}

\author{
Brahim KIDOU ${ }^{1}$ ๑, Hasna TNOURJI ${ }^{2}$, Nadia $_{\text {ATIKI }}^{3}$ ๑ \\ 1-2-3 Faculty of Arts and Human Sciences, IBN ZOHR University, Agadir, Morocco. \\ ORCID: B.K. 0000-0001-5560-5785; H.T. 0000-0003-3775-9398; N.A. 0000-0001-8783-8524
}

\section{ABSTRACT}

The settlement of Moroccan emigrants abroad dates back a long time, its beginnings coincided with the colonial settlement in Morocco. It has increased over the years and reached its peak in the last two decades, particularly towards the countries of Western Europe. Thus, this migratory phenomenon has diversified to generate different transformations in the migration process and in the demographic structure of the migrants, their destinations, and their types of integration and social advancement in the host countries. Its volume now exceeds five million individuals. Currently, the Moroccan immigrants are distributed differently in almost 100 countries in the world. The Moroccan community abroad reaches at present its third generation in the old host countries. Moreover, the participation of Moroccan immigration in the support of the Moroccan economy is still important.

Keywords: Moroccan Immigration, World, Characteristics, Dynamics aspects, Transformations. 


\section{INTRODUCTION}

Moroccan emigration abroad represents an old phenomenon of international migration. It began in the early 20th century, when French colonization activated it for its purposes. Over the years, this phenomenon has generated several changes and transformations in the migratory process, the demographic composition of migrants, their destinations and their types of integration and social advancement in the host countries. Moroccan migration then evolved quantitatively and qualitatively, in many directions, righting significant changes, which demonstrate to what extent the Moroccan community abroad, which marked several migratory basins in the world, has entered an unprecedented phase of advanced and varied transition.

The new demographic, spatial, socio-economic and cultural situations, that the international migration experience of Morocco has accumulated, is indeed receiving particular attention, and at the same time requires an analytical and comparative study of the characteristics that distinguish Moroccan immigrants, and this at several levels such as volume, spatial distribution, demographic structure, integration and role in their societies.

\section{OBJECTIVES AND METHODOLOGY}

This study is interested in exposing the new demographic, spatial and socio-economic characteristics and configurations that distinguish the Moroccan migration presence around the world. Also, this research will allow us to clear up the various forms of evolution and space distribution of Moroccans in the world, and to lead a geographical demo analysis, which compares and synthesizes, the current characteristics of the Moroccan immigration in the world.

The demo-geographical approach adopted in this study is based mainly on the exploitation of the data collected in the various systems of recording of the main host countries (France, Spain, Italy, Netherlands, Belgium, Germany, Canada, the United States ...), and it is in terms of stock in different years. This type of data has allowed us to follow the evolution of the population size on one hand, and to highlight the composition of this population observed at times on the other hand.

\section{BACKGROUND AND TRAJECTORY OF MOROCCAN EMIGRATION ABROAD}

The international emigration of Moroccans is an ancient phenomenon, its beginnings date back to the first decades of the 20th century. It was triggered by French colonization to meet its needs for fighters and labor. Its process has undergone many changes on several levels, such as: demographic composition, types of movements, destinations and socio-economic effects.

The geographical proximity of Europe, the demands of colonization army and economy, the crisis of rural areas and the hardness of economic and social living conditions in Morocco, the economic situation in the host countries and the immigration policy have been major factors that have had a concrete impact on the trend and pace of Moroccan international migration throughout its history. Generally, three distinct major stages have permeated the path of external Moroccan migration, namely:

- The colonial period: during which the first waves of migration were strictly linked to the orientations of the French colonial machine, and were also driven by the harshness of living conditions in Moroccan rural areas. Recruitment of Moroccan emigrants was carried out both as part of the reinforcement of the French army, and drained as agricultural and mining labor to meet the demand of the colonial economy.

- From independence to the end of the 1970s: the migratory phenomenon was regulated and governed by bilateral agreements with host countries. Indeed, the Souss and the Rif were the main areas of emigration abroad. Departures were directed specifically to France, Belgium and the Netherlands. The construction, mining, automotive and textile industries were the main sectors in which the Moroccan workforce was employed. Moroccan immigration has undergone structural changes and increased in numbers.

- From the 1980 s to present: Emigration affected other social categories (young people, women, students-experts, illegal immigrants...) and manifested new forms of migration. Other areas of emigration from Morocco to other countries appeared, notably Casablanca, Khouribga and Tadla. Similarly, migration has explored new migratory poles in Europe (Spain and Italy), Golf (Saudi Arabia) and North American countries. Thus, the number of Moroccans living outside has changed remarkably in many parts of the world. In addition, profound transformations and socio-economic relations have taken place within the Moroccan community abroad. 


\section{DYNAMIC ASPECTS OF MOROCCAN IMMIGRATION IN THE WORLD}

Morocco, departure point, is a country of about 34 million people. Its immigrant community adds up to 5 million people, or $15 \%$ of the total population. These nationals are unevenly distributed in almost 100 countries worldwide. Their high concentration is observed in Western Europe (+90\%).

The number of Moroccans residing abroad, which fluctuated around 2500000 persons towards the end of the 1990s, was almost doubled following an overall growth of 2301971 persons, recorded between 2000 and 2015, which has enabled the threshold of 5 million individuals implanted outside to be reached or even exceeded at present (Figure 1).

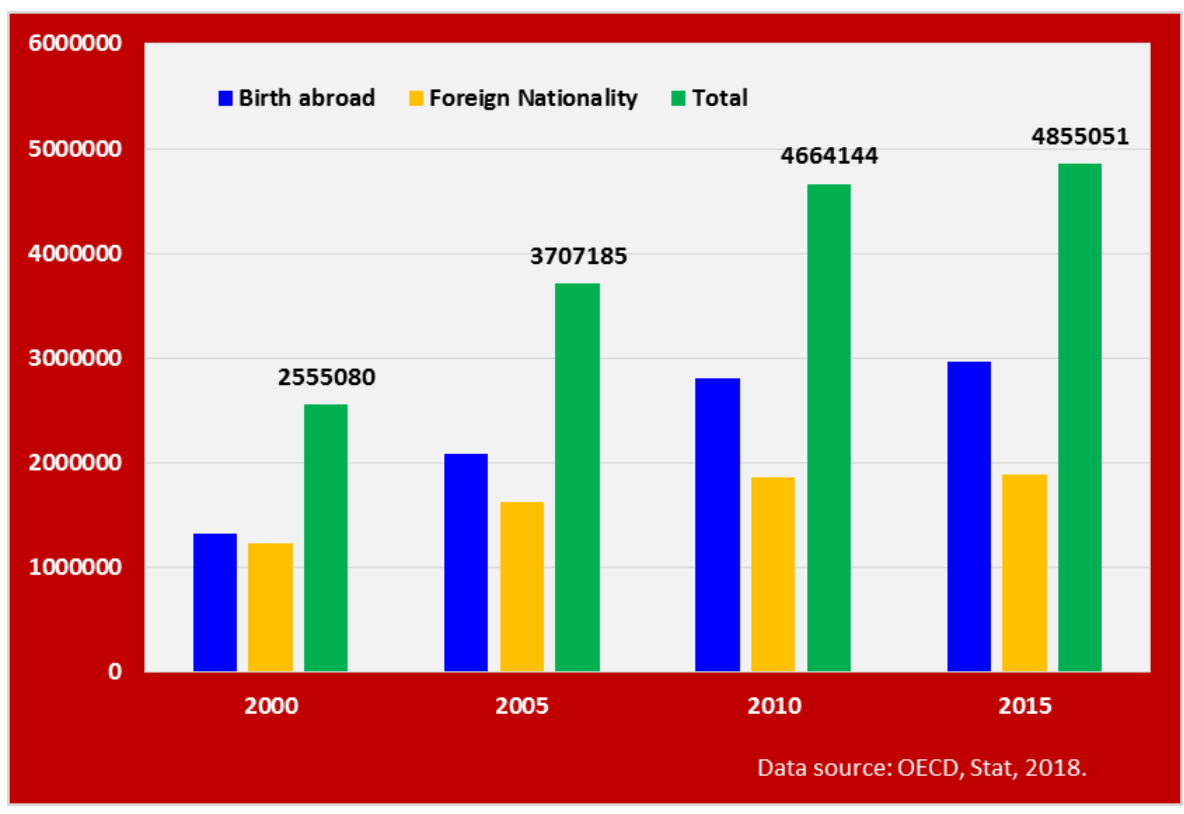

Figure 1: Evolution of the number of Moroccan migrants in the world according to the criterion of the census in the host country (2000-2015)

However, this growth varies according to the country of residence, it is high in the western European zone, particularly in Spain (11\%) and Italy (5\%). Moreover, the number of Moroccan migrants has increased significantly in recent years in the two North American countries, the USA and Canada, recording an absolute increase of +56951 people.

This recent demographic dynamism of the Moroccan population residing abroad is explained by two main factors, one endogenous and the other exogenous:

- For the first, it is due to the natural-internal demographic dynamics fuelled by new births or descendants of immigration, who are born abroad and form the second or third generation, depending on the host country. This no doubt testifies to a fertility sustained by an exceptional matrimonial dynamic which operates within the Moroccan immigrant community. In this sense, the relative weight of those born abroad is dominant, in 15 years (between 2000 and 2015), it has increased from 51 to $61 \%$.

- For the second, it concerns annual migration flows which continue to relatively support Moroccan settlement in several host countries (France, Spain, Italy, Netherlands, Belgium...etc.). These flows, which have become numerous, are either part of family reunification or studies, and sometimes of new casual recruitments and other reasons (Figure 2). 


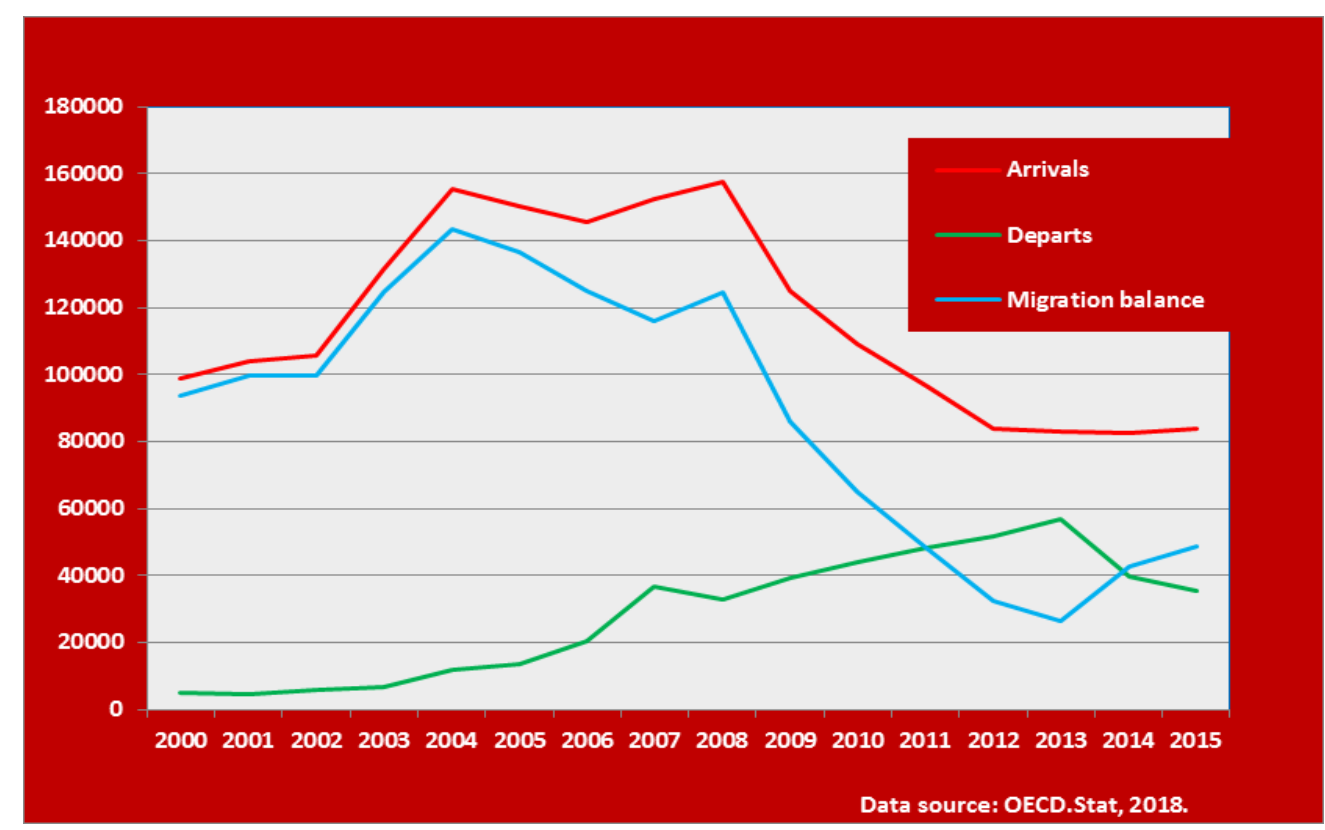

Figure 2: International movements of Moroccans (2000-2015)

Regarding the distribution of Moroccan immigration in the world, it should be noted that it today reflects a certain configuration with its historical evolution and its current trend. Of the Moroccan migrants, just over a third (34\%) are in France; the Moroccan nationals of this country are currently the oldest group of Moroccans migrating to the world. Spain and Italy are second and third respectively (20\% and 14.5\%) of Moroccan nationals in the world, followed by Belgium, the Netherlands and Germany. The other countries of Northern and Eastern Europe are home to only small numbers of Moroccan migrants (Map 1).

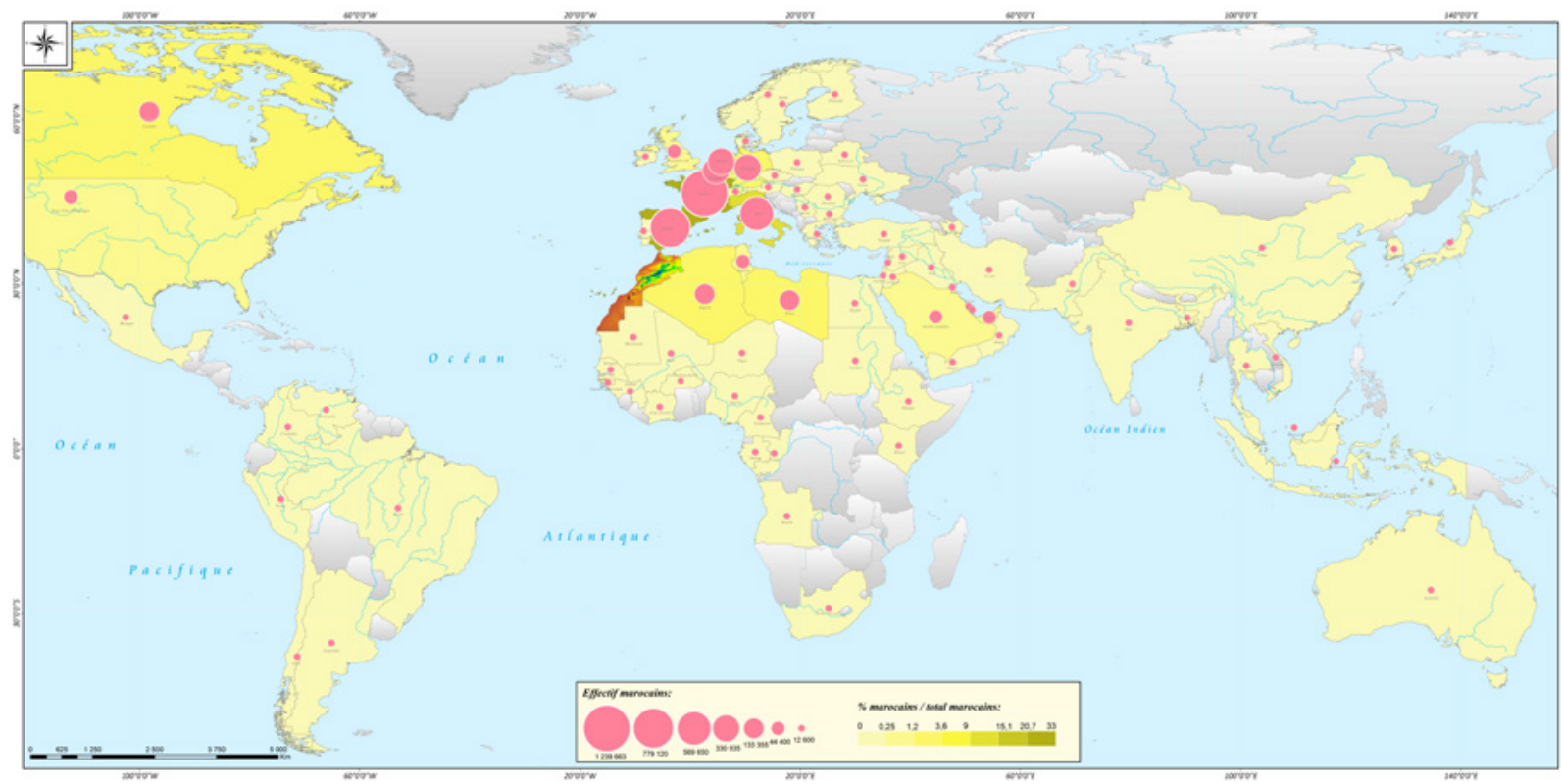

Map 1: Distribution of Moroccan migrants in the world (2014)

At the level of the Arab countries, Libya, which (before 2011) included a good part (69,276 people), came first, followed by Algeria (45,451 Moroccans), Saudi Arabia, and then Tunisia and the United Arab Emirates. This Moroccan emigration, which is relatively recent - except for Algeria - and which took place mostly through agreements between Morocco and the Arab countries, is almost a migration of workers. Its development is often subject to the direct influence of socio-political factors, including the degree of political stability, bilateral relations and job vacancies by host country. 
As for North America, Moroccan immigration is relatively recent, it is slowly asserting itself through the specific flows of managers, skills and young graduates, despite geographical remoteness and restrictions on access to this large and highly selective international migration hub.

\section{NEW FEATURES AND SITUATIONS OF MOROCCAN IMMIGRATION}

As a result of its demographic dynamics supported by the diversity and multiplication of its movements, Moroccan emigration to the world has taken on new characteristics that express the profound change it has undergone. These transformations have led to the demographic and social reconstruction of the Moroccan population migrating abroad, at the following levels:

- Its characteristic structure is distinguished by a relative balance between the two genders as a result of the changes that have affected the Moroccan immigration process (family reunification, autonomous female emigration), especially in France, Holland and Belgium. The case of France clearly illustrates this situation (Figure 3). The structural imbalance in Spain and Italy remains in favor of the male sex, especially in the adult and working age groups (Figure 4). In addition, its age composition is distinguished by youth and the preponderance of adulthood.

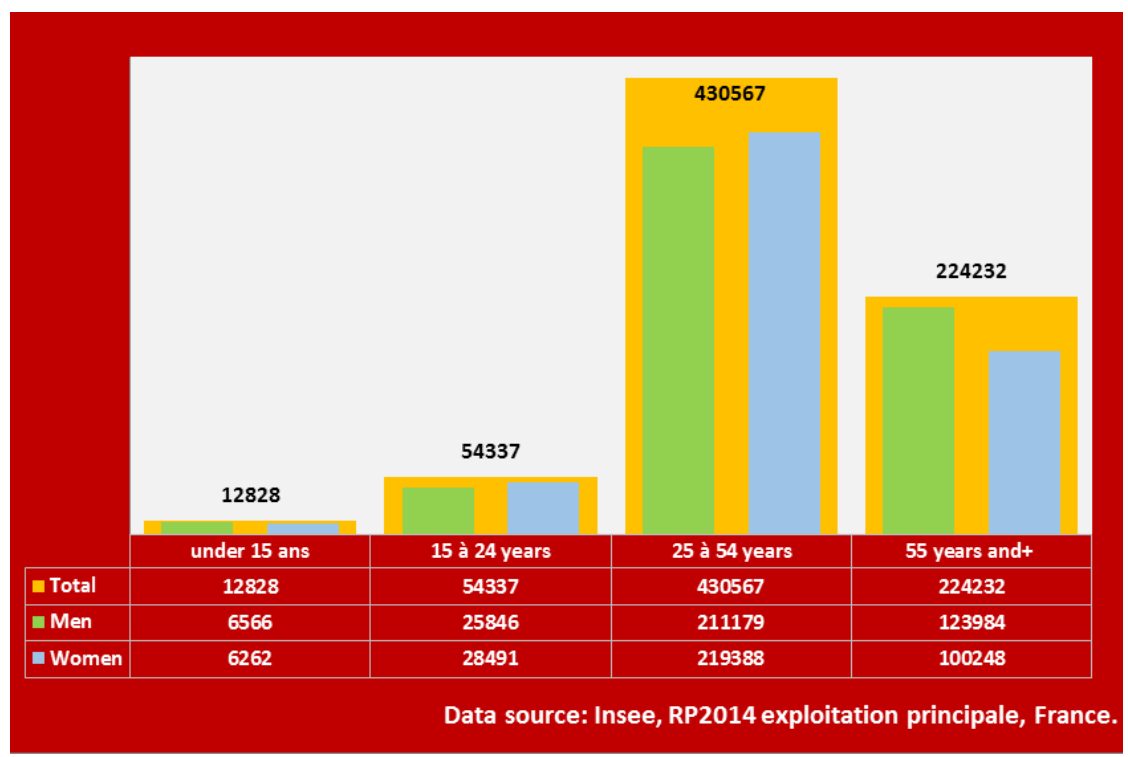

Figure 3: Moroccan immigrants by sex and age in France (2014)

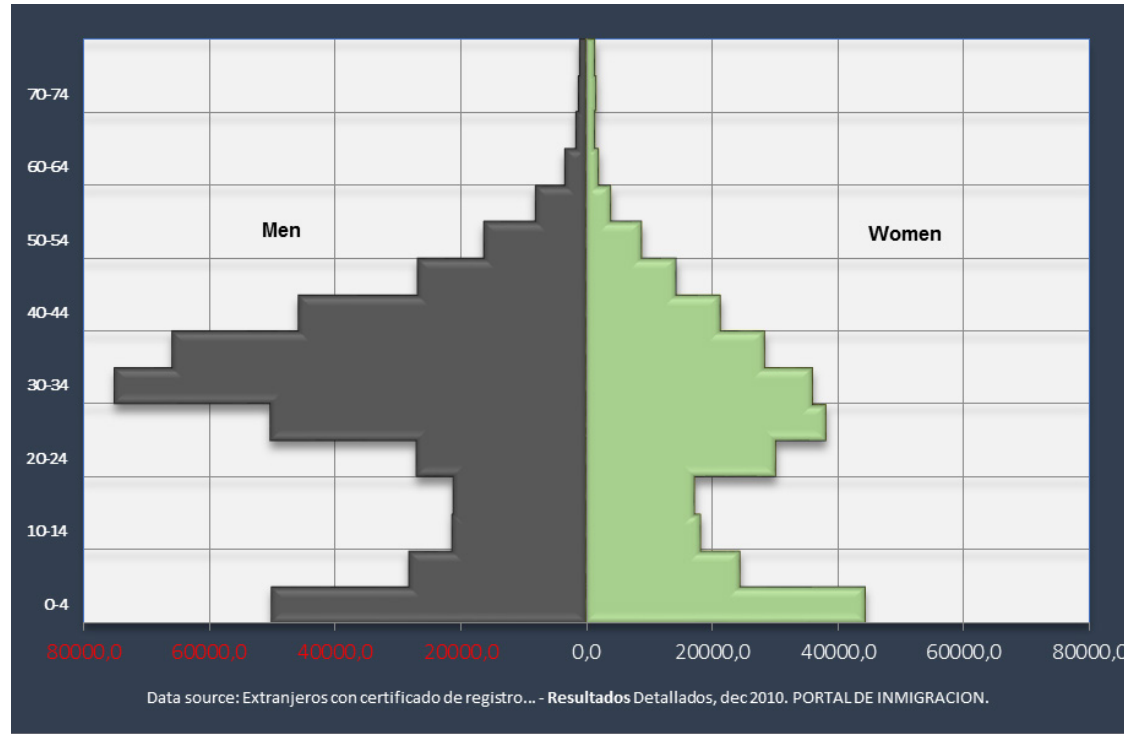

Figure 4: Sex and age structure of the total Moroccan community in Spain (2010) 
- Its distribution by field of activity varies and differs according to the economic sector, the host country and the demographic composition of the workforce. The tertiary sector is the most attractive sector of the Moroccan migrant labor force (48\%), followed by the secondary sector with $43.5 \%$. If the Moroccan working community in France is fairly equitably distributed among several sectors of activity (industry, construction, trade, transport, agriculture), the case is relatively different from other European host countries where active migrants of Moroccan origin are more restricted and dispersed according to the areas of activity that offer employment opportunities, trade, processing and agriculture. Moreover, it should be stressed that the change in the demographic and socio-cultural profile of Moroccan immigrants had enabled a good integration into the European economy. The improvement in educational attainment has had a significant impact on good professional development and the presence and integration of Moroccan workers into the European labor market (KIDOU, 2015).

- Its integration into the welcoming society is growing; because Moroccan nationals have been working intensively in recent decades, where conditions are met and allow it, to acquire the nationality of the host country. They make this choice as an effective legal means to acquire their full right of citizenship, and thus facilitate their full integration as a cosmopolitan citizen. As a result, the Moroccan community has become embedded and an integral part of the societal composition of the host countries, particularly in Europe, where it is no longer limited to providing a simple hand, as was the case for the first generations. It provides skills in all fields, and has a multitude of social, spatial, cultural, demographic and political effects. Morocco also benefits through the experiences, know-how and technologies that migration skills transfer to their countries of origin.

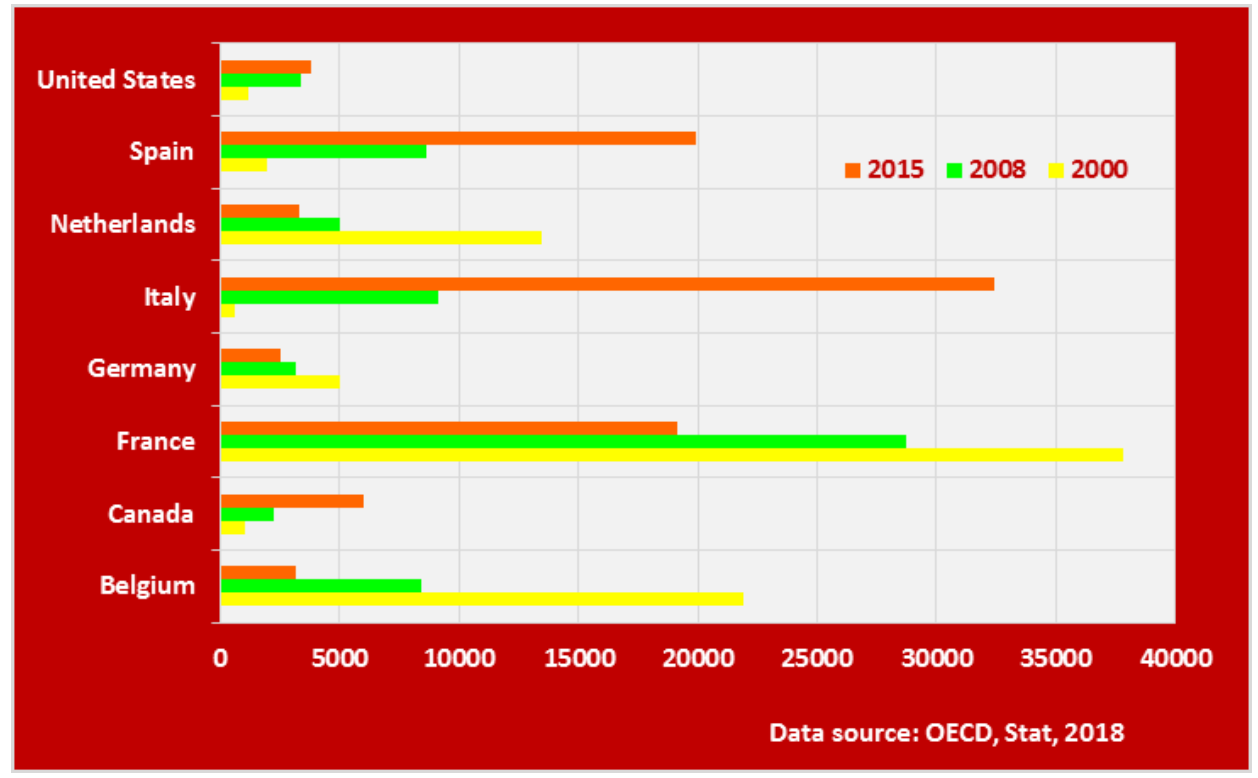

Figure 5: Evolution of number of Moroccans who acquired citizenship in the host country between 2000 and 2015 (more than 1000 persons naturalized)

- Its economic and social impact is significant, as it has been shown that the economic effect of Moroccan emigration is predominant, given the important role of cash transfers in the promotion of development projects. Indeed, the remittances of the world's Moroccans represent not only a strong expression of social solidarity and attachment to the country of birth, but also an important source of support to the Moroccan economy, and this through the investments it induces in various fields of economic activity. 


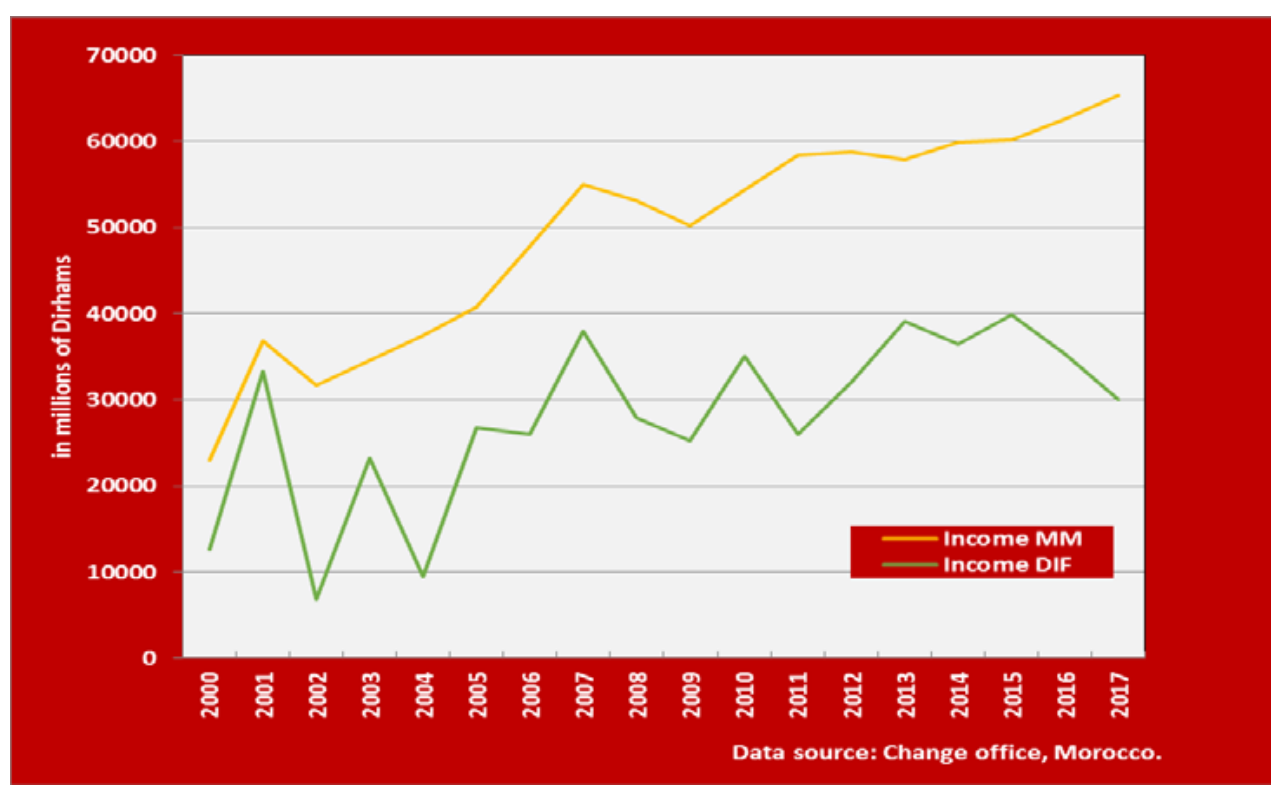

Figure 6: Comparative evolution of remittances by Moroccan migrants compared to foreign direct investment in Morocco (2000-2017).

This development has been observable since the Moroccan State embarked on the path of reforms, modernization, revitalization and encouragement of investments in various sectors of economic activity. The annual receipts, which come from the cash transfers of the world's Moroccans, appear to fluctuate depending on the month and year, but they also show an upward trend from one year to the next. The total amount, which did not exceed 23 billion dirhams in 2000, was multiplied by 2.8 to reach more than 65 billion dirhams in 2017 (Figure 6). Moreover, this annual growth in remittances remains uneven depending on the country of reception of Moroccan immigrants. It depends, of course, on the demographic weight of migrants according to their place of residence, the quality of the jobs they perform, but also on the efforts made to encourage them to participate in favor of the country of origin.

\section{CONCLUSION}

Moroccan migrants residing abroad are not only a distinct community still attached to its origins, but also a remarkably integral part of the international migration system, their migratory process, their characteristics and their roles. Moroccan immigration, which dates back to the beginning of the last century, brought about significant changes in its demographic structure, which has become more composite, and its distribution throughout the world is fragmented, its integration, which is becoming more and more evident in the different host countries, and its unavoidable socio-economic impact, carried out in both directions of migration, origin and destination. The new characteristics which distinguish it today are mainly due to its sustained dynamics in recent decades, both by internal growth and by new migratory flows. 


\section{REFERENCES}

Atouf, El. (2009). The historical origins of Moroccan immigration in France: 1910-1963. Paris, Connaissances et Savoirs. (in frensh) Batalova J., Shymonyak A., Mittelstadt M. (2018). Immigration data matters, Migration Policy Institute. Population Reference Bureau. March 2018. (in frensh)

Baylac, A. (2015). The origins of Moroccan immigration in Midi-Pyrénées. In les Cahiers de Framespa bvn,]on ligne [, 19/2015, URL, http:// framespa.revues.org/3319. (in frensh)

Bokbot, M., Faleh, A. (2010). A century of Moroccan emigration to France: historical overview. In Papeles de Geografia, 51-52 (2010), 55-64. (in frensh)

El Asri, F. (directed by) (2013). Moroccan migration: Moroccan skills abroad, 25 years of mobilization policies. Council of the Moroccan Community Abroad (CCME). Rabat, Morocco. (in frensh)

EUROSTAT. (2018). Population-migration. Data 2018.

Hein De Haas. (2005). Morocco's migration transition: Trends, determinants and future scenarios. MDR Working, Paper No. 3 “Migration and Development Revisited". A WOTRO/NWO research project, March 2005.

IMMIGRATION DATA MATTERS. (2018). Migration Policy Institute, March 2018.

INTERNATIONAL MIGRATION REPORT 2015. MIGRATION, EMIGRATION AND DEVELOPMENT IN A CHANGING ARAB REGION. United Nations Economic and Social Commission for Western Asia (ESCWA), United Nations. (in arabic)

INTERNATIONAL ORGANIZATION FOR MIGRATION. (2018). State of Migration in the World 2018. Genève, Suisse. Global Migration Data Analysis. Center (GMDAC) \& International Organization for Migration (IOM) (2018): «Global Migration Indicators 2018 », Berlin, Germany.

Kidou, B. (directed by) (2015). Atlas of the World Moroccans 2015: General characteristics. Council of the Moroccan Community Abroad (CCME). Rabat, Morocco. (in frensh/arabic)

Kidou, B. Tnourji, H., Atiki, N. (2016). Contribution to the synthetic mapping characteristics of the change of the international Moroccan migration. The 33rd International Geographical Congress: Shaping Our Harmonious Worlds, 21-25 August 2016, Beijing, China.

Organization for Economic Co-operation and Development (OECD). stats.oecd.org/. (DEMOGRAPHY-POPULATION-INTERNATIONAL MIGRATION). Data 2018.

POPULATION CENSUS. (2014). MAIN OPERATION 2016, National Institute of Statistics and Economic Studies (INSEE), France.

REGIONAL REPORT ON ARAB INTERNATIONAL MIGRATION, INTERNATIONAL MIGRATION AND DEVELOPMENT. (2014) Arab League, Social Affairs Sector for Population Policies, Emigrants and Migration, 127p. (in Arabic)

RESIDENT FOREIGNERS: MAIN RESULTS. (2017). Immigration Portal, Spain. (in Spanish) 